Article

\title{
Still 'Watching' TV? The Consumption of TV Fiction by Engaged Audiences
}

\author{
Alexander Dhoest ${ }^{1, *}$ and Nele Simons ${ }^{2}$ \\ ${ }^{1}$ Department of Communication Studies, University of Antwerp, 2000 Antwerp, Belgium; \\ E-Mail: alexander.dhoest@uantwerpen.be \\ ${ }^{2}$ Faculty of Design Sciences, University of Antwerp, 2000 Antwerp, Belgium; E-Mail: nele.simons@uantwerpen.be \\ * Corresponding author
}

Submitted: 21 August 2015 | Accepted: 20 November 2015 | Published: 14 July 2016

\begin{abstract}
There is no denying that television, as a medium and an institution, has drastically changed in the age of digitization and convergence. For audiences, this has not only opened up multiple opportunities to watch television content at other times and on other devices, but also to interact with its cross-media extensions. However, while much has been written about the new opportunities for audience engagement, we do not know much about the actual adoption of new technologies nor the motivations underlying such uses. Therefore, this paper draws on empirical audience research to address the key question: how do viewers engage with contemporary TV fiction? Through empirical audience research, using various qualitative research methods, three different aspects of the reception of cross-media TV fiction will be discussed: (1) how do viewers watch the TV episodes of contemporary TV fiction?, (2) how do viewers engage with the cross-media extensions of TV fiction?, and (3) how do viewers experience the social dimensions of contemporary TV fiction? We focus on a particular group, that of 'engaged' viewers, who are actively involved by personalizing their viewing practices, by communicating about it, by consuming cross-media elements of TV fiction, or producing TV fiction-related content. Our findings suggest that even this group does not make full use of all the available technological opportunities to personalize TV viewing, and that the classical TV text, linear viewing, and the social aspect of viewing remain of key importance.
\end{abstract}

\section{Keywords}

cross-media; Flanders; in-depth interviews; TV fiction; TV viewing

Issue

This article is part of the issue "(Not Yet) the End of Television", edited by Milly Buonanno (University of Roma "La Sapienza", Italy).

(C) 2016 by the authors; licensee Cogitatio (Lisbon, Portugal). This article is licensed under a Creative Commons Attribution 4.0 International License (CC BY).

\section{Introduction}

From the mid-2000s onwards, the future of television has been a hotly debated topic, both in journalistic and in academic writings, as the introduction of a range of digital technologies entailed substantial adjustments to the medium's form and use. Although television has continuously evolved since its inception, the multitude of changes and possibilities introduced by digitization was perceived as more transformative than ever. Digitization has detached television content from the televi- sion screen and stimulated convergence; more than ever, boundaries between TV and other media blur. A number of concepts have emerged in an attempt to grasp the increasing migration, integration and interaction of television content across a range of platforms (Caldwell, 2006). Beside broadly accepted terms like 'convergence', 'franchise', 'synergy', 'multiplatform' and 'cross-media', more author-specific concepts such as 'transmedia storytelling' (Jenkins, 2003, 2006), 'overflow' (Brooker, 2001), 'paratexts' (Gray, 2008, 2010), 'expanded TV text' (Askwith, 2007), 'add-ons' 
(Brereton, 2007), 'media tie-ins' (Clarke, 2009), or 'bonus tracks' (Boccia Artieri, 2012) are all used to describe the phenomenon of television extending beyond the television set and to other media.

Academic articles and books on television and its future, with titles such as 'The television will be revolutionized' (Lotz, 2007), 'Television after TV' (Spigel \& Olsson, 2006), 'Television studies after TV' (Turner \& Tay, 2009), or 'Television 2.0' (Askwith, 2007), not only assume a drastic change-if not 'the end'-of television; they also tend to focus on industrial and technological changes, without empirically substantiating the actual adoption of the new possibilities these entail for audiences. Bold statements about television viewing practices - such as 'the nature of our television use has become increasingly complicated, deliberate and individualized' (Lotz, 2009a, p. 2), and 'watching television is evolving into an active perpetual process that happens everywhere and at all times' (Askwith, 2007, p. 12)-are often made without consulting the audience. These claims are based on the opportunities digital technologies create for viewers and on generalizing expectations about audience behaviour, rather than on actual practices and experiences. Therefore, this article will draw on empirical audience research to address the key question: how do viewers engage with contemporary television? We argue that empirical audience research is vital in a discussion about the future of television, as viewers are determinative for the evolution of the medium through their (non-)adoption of certain viewing opportunities. In our research, we focus in particular on Flanders, the northern Dutchspeaking part of Belgium, and on fiction, as this is one of the key genres in terms of 'new' audience practices such as digital recording, downloading and 'binge viewing'. In this research, we do not only address 'classical' TV texts but also their cross-media extensions. Three different aspects of TV fiction consumption will be discussed: (1) how do viewers watch the TV episodes of contemporary TV fiction? (2) how do viewers engage with the cross-media extensions of TV fiction? and (3) how do viewers experience the social dimensions of contemporary TV fiction? But before we do this, it is necessary to briefly discuss the characteristics of contemporary television.

\section{TV Fiction in the Age of Digitization and Convergence}

Lately, much has been written on the future of television. Although opinions diverge-from the death of broadcasting to the rise of user-generated online content-all agree that new versions of television are emerging that differ in crucial ways from its original industrial organization and social role (Lotz, 2009b, p. 50). Many scholars use a three-way division to structure the history of television (see e.g. Ellis, 2000; Lotz,
2007; Rogers, Epstein, \& Reeves, 2002).

The first era is that of broadcast television, alternatively named the 'era of scarcity' (Ellis, 2000, pp. 39-60), the 'network era' (Lotz, 2007, p. 7) or 'TV I' by (Rogers, Epstein and Reeves, 2002, p. 55). In this period, the medium is characterized by a limited number of channels which broadcast only for part of the day. Television presents definitive and fixed programming to a mass audience; viewers can only access shows at appointed times in a routinized daily sequence of programming (Lotz, 2009b). In Belgium, as in many other European countries, this is the era of a public service broadcasting monopoly, financially supported and controlled by government. In terms of viewing practices, this period is characterized by immediacy, as the images on the screen are constantly changing, disappearing the moment they have appeared. Moreover, the structure of the broadcasting schedules reflects assumptions about the routines of everyday life (Bennett, 2011). Broadcasting television's immediacy limits the viewers' agency: viewers can tune in and (only) watch whichever show is broadcast (Evans, 2011). Television in the era of scarcity is a 'push environment': the linear daily sequence of programming is 'pushed' to the viewers and leaves them with minimal control (Gripsrud, 2010; Lotz, 2009b). Finally, television in this era is considered as 'social', addressing a unified national audience conceived as a collective of families watching together in the domestic sphere. One of the key characteristics of linear broadcasting is that millions of viewers are watching the same content at the same time. This synchronicity plays a vital role in creating a sense of being part of a particular audience. Watching traditional linear television is 'watching with', according to Milly Buonanno (2008, p. 24), meaning 'watching with all the other distant and unknown viewers whom one supposes or guesses are simply there in front of their screens at the same time as we are in front of ours, watching the same programme or part of a programme that we are watching ourselves'.

The second era is that of cable and commercial television, multiple channels competing for the viewers' attention and introducing the 'era of availability' (Ellis, 2000, p. 61), a 'multi-channel transition period' (Lotz, 2007, p. 7), or the era of 'TV II' (Rogers, et al., 2002, p. $55)$. While the era of scarcity is characterized by social unity, the era of availability is characterized by social differentiation and choice (Ellis, 2000). The mass audience from the previous era is fragmented into niche audiences who turn their attention to specialised channels (Askwith, 2007). Across Europe, including Belgium, public service broadcasters loose audiences to commercial channels right after their introduction. TV stations begin to develop well thought out broadcasting schedules in order to create a specific channel identity and to attract and retain viewers (Aronson, Reddy, \& Stam, 1998). There is also a shift in agency from the 
networks to the viewers. Technologies giving power and control to the viewer, such as the remote control device and the video cassette recorder (VCR), are emerging (Lotz, 2009b). In this second era, the audience gets more dispersed because of the evolution from few channels to many channels, from broadcasting to narrowcasting, and because of the introduction of the first time-shifting technology (Lotz, 2009b).

The third and current era is that of digitization and convergence. In the new millennium, television starts moving into the 'era of plenty' (Ellis, 2000, pp. 162178), the 'post-network era' (Lotz, 2007, 2009b), the 'post-broadcast era' (Turner \& Tay, 2009b), or the phase of 'TV III' (Rogers, et al., 2002, p. 55). In this era, the diversification of the production and distribution of TV content that started in the second era continues and flourishes (Buonanno, 2008). Most changes can be ascribed to digitization: the digital transmission of television signals, but also the adoption of digital technologies in the production and reception of television (Lotz, 2007). The digital video recorder (DVR) and the personal video recorder (PVR) allow viewers to easily split up the flow of content into individual programmes that can be reordered, saved and re-viewed (Askwith, 2007; Lotz, 2009b). Partly in response to the threat of these convenience technologies, many television providers embrace video-on-demand (VOD) distribution technologies that allow viewers to purchase and watch individual programmes whenever they choose (Askwith, 2007). TV programmes are also made available on the computer by streaming or downloading through specialised websites (Van den Broeck, Pierson, \& Lievens, 2007). In short, the interfaces and platforms through which a viewer can access television programmes have multiplied exponentially.

Digitization also enables media convergence, understood here as a multi-faceted process that refers to 'the new textual practices, branding and marketing strategies, industrial arrangements, technological synergies, and audience behaviours enabled and propelled by the emergence of digital media' (Kackman, Binfield, Payne, Perlman, \& Sebok, 2011, p. 1). As convergence allows viewers to share 'television' content among their televisions, computers, mobile phones and other devices, content boundaries among screen technologies disintegrate (Lotz, 2007). What used to be television programmes is now evolving into 'content' that can be distributed and accessed on various platforms (Askwith, 2007). In terms of viewer practices, timeshifting and location-shifting technologies make traditional assumptions about the television viewer impossible, since networks no longer have the power to control when, where or how audiences consume their programming (Askwith, 2007). The converged and overcrowded media landscape results in an intense competition to attract and retain audiences. Henry Jenkins (2006, pp. 20, 61-62) defines this as 'affective economics': a marketing logic in which branding is the key concept, seeking to understand the emotional underpinnings of consumers' decision making as a driving force behind viewing and purchasing decisions. The aim is, firstly, to stimulate emotional engagement and create loyal brand communities. Secondly, this brand loyalty is then supposed to generate new revenues by making content available through a variety of screen technologies and releasing additional possibilities for viewer engagement

Because of these innovations, all the established knowledge about how audiences watch television is called into question. The time structuring element, the liveness and immediacy that were so typical for broadcasting television, are further challenged by digitization. As television viewing devices become more complex, digital, and networked, the opportunities for customization, personalization, and control increase. It is suggested that these changes shift the control or 'agency' over the programme schedule from the networks to the viewers (e.g., Carlson, 2006; Evans, 2011; Hoppenstand, 2006; Lotz, 2007; Mittell, 2011). In this sense, television does not consist of a flow of programmes available at a particular moment anymore, but it has become a platform for content, a 'library' with 'files' (Buonanno, 2008; Mittell, 2011), to be recorded, saved, viewed and re-viewed on-demand. The viewing environment evolves from a passive 'linear push environment' into an active 'non-linear pull environment', meaning that the viewer can pull the desired content (Gripsrud, 2010). Moreover, consuming TV content can consist of much more than just viewing as TV programmes are expanding to other media. Askwith (2007, p. 12) even states that the practice of consuming TV content is transforming from 'a passive process that happens in front of the screen into an active, perpetual process that happens everywhere and at all times'. Indeed, TV programmes that combine television with a brand website, online video, books, and other merchandize, invite viewers for an investment and immersion through a variety of (interactive) activities.

These changes also influence the social nature of TV consumption, as they have detached television content from the centrally placed television screen (Lotz, $2009 b$ ). Not only is television content available on the different television sets in the house, it is also available on computer screens, mobile phones and other portable devices. This implies that the act of watching television might become less social: the family viewing experience might disappear as family members now have different screens to watch TV content on. As a consequence, family members might no longer watch together but might spread out into separate rooms, which Elihu Katz (2009) describes as a move from a 'collectivist' phase to an 'individualist' phase. According to Katz $(2009$, p. 7) the television of 'sharedness' is no longer with us, having made room for a television of 
hundreds of channels, of 'niche' broadcasting, of portability, one that is part of a system that integrates with the internet and other new media. Similarly, societywide viewing of particular programmes was once the norm, but has now become an uncommon experience (Lotz, 2007). While linear broadcasting television joins people, keeps them together and unifies nations (Buonanno, 2008), post-linear television isolates and separates.

But does it really? Many of the claims made above are based on observations at the macro level, and focus on what is possible rather than on actual audience practices. While we do not question the overall changes described above, we do wonder what audiences actually 'do' in this new media landscape, and why. To explore this, the remainder of this article will discuss the findings of empirical research on the practices and motivations of contemporary TV 'viewers'.

\section{Methods}

As mentioned above, the research presented in this article was conducted in Flanders, the northern Dutchspeaking region of Belgium. In order to sharpen the focus of our study, we decided to narrow down our empirical research to TV fiction (including fiction series, serials, soaps and sitcoms), as previous research (e.g. Askwith, 2007) indicates that TV fiction is most likely to be time-shifted. Furthermore, as this study focuses on changing viewing practices for TV fiction and the reasons for these practices, the sample for this study consists of engaged TV fiction viewers, defined here as viewers who do more than just watching fiction through live broadcast television. They are actively involved with TV fiction in different ways: by personalizing their viewing practices (when, where and through which technology), by communicating about it, by consuming cross-media elements of TV fiction, and/or by producing TV fiction-related content. They are 'heavy consumers' or 'intense users' of TV fiction and 'early adopters' of new TV and media technologies. In other words, they are 'information-rich cases' (Creswell, 1998, p. 119) with regard to our object of study. This form of intensity sampling (Ritchie, Lewis, \& Elam, 2003, p. 79 ) is very useful to research audiences in a constantly changing media landscape. First of all, in order to explore the reasons behind new and emerging media practices, it is necessary to select participants who are early adopters of these practices. Second, although these are only the initial uses of an unrepresentative group, these participants might provide us with clues about future uses of a broader population (Barkhuus, 2009; Lotz, 2007).

In order to select our sample, we set up a preliminary online survey enquiring into different ways of engagement with TV fiction. Respondents with high scores were approached to participate in the actual re- search. A total of 1,169 filled in the preliminary online survey. 157 people met the needs of the research and were interested in participating. In the end, 61 people (39 men and 22 women) completed the whole research process, ranging in age from 17 to 55 years. For the data collection we used TV diaries in combination with indepth interviews. An online action based-instead of time based-TV diary was designed to chart how viewers engage with a TV show and its add-ons through different media platforms. Each day during one month, the participants reported all their actions (viewing, downloading, gaming, talking, shopping, reading, etc.) related to TV fiction in their online TV diaries. After the TV diary month, the research process was concluded with an in-depth interview, in which the reasons behind the various viewing practices were explored. During the interview, a copy of the completed TV diary was used to recall the actual viewing practices. In addition, to collect specific information about cross-media engagement, we conducted six focus groups with five to eight fans of the drama series Lost, Stargate Universe, True Blood, and Gossip Girl, and two focus groups with fans of the Flemish soap Thuis. Most of the participants for these focus groups were selected from the database of the preliminary online survey, while others were contacted via already selected participants based on their recommendations. All these interviews were recorded, transcribed and analysed using the NVivo qualitative data analysis software. In what follows, the key findings and broad patterns rather than the detailed findings will be discussed, in order to come to an overarching answer to our research question.

\section{Viewing Practices in the Digital Era}

In our analysis, we focused on three subquestions to the main research question 'how do viewers engage with contemporary television?': (1) how do viewers watch the TV episodes of contemporary TV fiction, (2) how do viewers engage with the cross-media extensions of TV fiction, and (3) how do viewers experience the social dimensions of contemporary TV fiction?

First, we explored how viewers engage with the core content of TV fiction by examining how viewers watch the episodes of contemporary TV fiction. Through the TV diaries and in-depth interviews, we discovered an array of different viewing practices. These are related to different ways of time-shifting, as each viewing practice involves departing from the original moment of broadcasting to a certain extent. Three different levels of time-shifting can be distinguished, each with various categories: time-shifting on the level of technology (live television, digital video recording, downloading, or DVD), time-shifting on the level of the release date (original release date, Flemish release date, or DVD release date), and time-shifting on the level of the viewing rhythm (one episode or multiple 
episodes). Certain categories of the three time-shifting elements coincide more than others, and together they form a continuum of viewing styles, through which the participants shift depending on external factors such as the origin or type of TV fiction, and the day and time of broadcasting.

Another important factor in this continuum of viewing styles are the reasons for time-shifting, where two main reasons recur: being in control, and the social context of viewing. First, we found that some of the participants prefer to be in control over when they watch and what they watch, while others prefer not to. For some viewers the feeling of being in control is necessary in order to be able to enjoy TV fiction, while for others the joy of watching TV fiction stems from not having to make any decisions about the time and content of viewing. The responses of the participants reveal that 'convenience' is the underlying common motive for these apparently opposite reasons. Watching TV fiction is perceived as a leisure activity, and thus must happen in the most convenient way. While new technological possibilities offer increasing power and control to the viewer, our research indicates that not everyone is looking for such control. Second, the social context also came forward as a dominant reason to opt for a certain viewing practice, whether by adapting the viewing practice in order to watch together or individually, or in order to discuss the episodes offline or online. While digitization enabled full flexibility and the industry predicted the rise of individualized and personalized viewing practices ('me TV'), the participants in this research seem to still value the social aspect of watching TV fiction a lot. ${ }^{1}$

Second, we analysed the use and reception of crossmedia extensions of TV fiction. Here, our different research methods led to different results. Based on the TV diaries, the actual consumption of cross-media extensions was listed. These data show that such extensions are commonly consumed, especially the marketing driven cross-media extensions. However, analysis of the in-depth interviews and focus groups demonstrated an overall disinterest in opportunities for engagement with TV fiction through other media platforms. The large majority of the participants consume the TV fiction extensions almost by coincidence (stumbling upon them whilst using different media) and are not looking for a strong involvement with interactive media. Active viewer participation is not something they are consciously looking for: most viewers describe 'engaging with TV fiction' as 'watching TV episodes' and not as being actively involved through multiple media. The lack of enthusiasm for cross-media extensions can be explained by the mismatch between the viewing motivations as expected by TV producers and

${ }^{1}$ For a more elaborate discussion of these findings, see Simons (2013). the actual motivations of viewers. While TV producers seek an audience looking for immersion in a multiplatform narrative story, the viewers we researched are mainly interested in being entertained by TV episodes. Hence, we can conclude that cross-media extensions of TV fiction are being evaluated in the light of the established form of engagement the viewers already know, namely the TV episodes. ${ }^{2}$

Third, we explored the social dimensions of consuming cross-media TV fiction by looking at the audiovisual TV fiction experience as a whole. After a qualitative analysis of the TV diaries and in-depth interviews, we discovered three dimensions in the social experience of engaging with TV fiction. First, viewers are watching together (especially Flemish TV fiction), for different reasons: practical ones (e.g. there is only one TV set), out of habit (it is a daily routine) or to have a better perception (a shared TV experience is a richer experience). Second, they are discussing TV fiction offline (short and usually superficial conversations) and online (more in-depth and substantive discussions) in order to share the experience with fellow viewers. Third, a few participants interact online with fictional TV characters and see this as a way to get closer to the show. The large majority of our participants thinks that discussing TV fiction is a fundamental part of 'following' a show and while doing so, many say they experience a sense of belonging to a certain television audience. Clearly, for these viewers consuming TV fiction is still a shared and social experience. Hence, we can conclude that new media technologies have not only divided the audience by providing time-shifting technologies, but have also brought viewers closer together by facilitating new options to watch TV fiction and talk about it with fellow viewers. ${ }^{3}$

Connecting the findings of these three analyses, we can distinguish different viewing styles. Each of these viewing styles is a combination of time-shifting practices (on the level of technology, release date and rhythm), ways of (not) consuming cross-media extensions, and social practices. The live viewing style is characterized by watching live at the moment of broadcasting, following the broadcasting rhythm (one episode at the time) and release date. This is a typical social viewing style: viewers choose to watch live in order to watch together with others and/or to discuss the episode afterwards. In our study, this live viewing style is also characterized by the consumption of some cross-media elements, such as a soap blog.

The delayed viewing style is characterized by watching Flemish or international TV fiction delayed (by recording or buying via DTV), at a better suited moment.

\footnotetext{
2 For a more elaborate discussion of these findings, see Simons (2014).

${ }^{3}$ For a more elaborate discussion of these findings, see Simons (2015).
} 
The original broadcasting rhythm is still followed and the episodes are watched when released on Flemish TV channels. With this viewing style the direct social context is often decisive for the moment of watching (time-shifting), but there is less (online or offline) social interaction about TV fiction afterwards. Furthermore, in this viewing practice style there is very little consumption of cross-media elements.

Next, the downloading viewing style is characterized by consuming international TV fiction, downloaded at the original (usually American) release date and watched following the broadcasting rhythm (one episode at the time) or at one's own rhythm (multiple episodes at the time). Viewers who adopt this viewing style usually watch individually but often have online social interactions after watching. With regard to the consumption of cross-media elements, very little consumption can be noticed, as only real fans engage online.

Finally, the DVD viewing style is characterized by watching TV fiction on DVD, at a self-determined moment and rhythm, usually multiple episodes at a time. These are often group viewing sessions, so there is immediate social interaction while watching, but very little social interaction with regard to the series afterwards. In this viewing style, there is very little engagement with cross-media elements, except for the consumption of TV fiction related merchandize.

Overall, we found that most of the participants in this study switch between different viewing styles, but the large majority predominantly watches live at the moment of broadcasting, or almost live. Time-shifting technologies are being used to delay the moment of watching, which is usually only a bit later in the evening. The television medium is still key for the reception of fiction, as watching the episodes is the main ingredient in the engagement with cross-media TV fiction and the consumption of the expanded TV text plays only a marginal role. The social dimension is also important in viewers' engagement with cross-media TV fiction, as it determines how, when and where people watch the episodes and whether they interact with the crossmedia extensions.

\section{Discussion and Conclusion}

Returning to the changes in television as outlined in the literature review, we can now situate and discuss the implications of our empirical findings. First, with regard to viewing practices, a shift in control is generally observed, from the broadcasters to the viewers. Looking at the results of our study, it is clear that the participants do not make full use of all the technological opportunities to personalize TV viewing. Many of the participants still watch a lot of TV fiction (usually Flemish TV fiction) at the moment of the live broadcast. Moreover, although the participants do use a variety of time-shifting technologies, they do not actually view TV fiction episodes à la carte. Time-shifting can happen at (a combination of) three different levels (technology, the release date, and the rhythm of watching), but this usually results only in slightly delayed viewing, from a few hours to a day after the original broadcast. Whether they watch locally or internationally produced fiction, most participants still follow the broadcasting rhythm of weekly episodes instead of, for example, saving them all up to watch at a selfdetermined pace. While the agency-or increased control-that digitization brings is generally perceived as liberating, this is not the case for all viewers. For some, video-on-demand services and downloading offer an appreciated alternative to break free from television's temporal structure, which is necessary to properly enjoy TV fiction. For others, this enjoyment stems from not being in control and not having to make any decisions about the time and content of viewing. Thus, while the technological possibilities offer increasing power and control for the viewer, this study indicates that not everyone is looking for such control. Convenience seems to be the key explanatory factor here: as they watch TV fiction in their leisure time, viewers adopt the most user-friendly and convenient viewing style, which sometimes includes time-shifting technologies (taking control) and sometimes not (leaving control to the broadcaster). Based on these findings, it seems that the new viewing practices that have appeared when digital time-shifting technologies were introduced, have not replaced the modes of viewing that were dominant in the previous eras of television; rather, they exist side by side, as Lotz (2009a) and Bennett (2011) have also argued. There is a continuum of viewing practice styles, with more control for the broadcaster on one end and more control for the viewer on the other.

Second, concerning the evolution of the TV text, the literature suggests a shift from divergent singlemedium TV fiction to convergent cross-media fiction. Looking at our empirical findings, it is clear that television is still very crucial in the engagement with contemporary fiction. The television episodes are the main ingredient of our participants' fiction experience. Moreover, even the extended texts are perceived as 'television content': whether accessed through television or another technology, and whether consumed as episodes or in another format, the content is still labelled as 'television'. Similar to what Evans (2008) found, the viewers in this research consider fiction extensions in terms of what they already know: the episodes. The television text is still the central point in their experience, to which other extended texts-if used-are compared. Engaging with TV fiction means watching the TV episodes and does not necessarily include a range of other mediated activities, as was predicted by some scholars (e.g. Askwith, 2007). The results reveal an overall disinterest in actively engaging 
with cross-media fiction through various media platforms. The viewers want to experience the narrative storyworld through audio-visual content, preferably on a TV screen. They are not in favour of taking on an active role in the unfolding of the story, as this would hinder rather than improve immersion in the fictional world. To sum up, with regard to cross-media TV fiction, the media use of the participants in this research is characterized by divergence rather than convergence.

Third, according to the literature discussed above TV is supposed to have evolved from a collective community medium to an individualistic ' $m e$ ' medium. However, our research shows that the social aspect of TV viewing and engaging with TV fiction remains very important. The social context is one of the main determinants for the chosen viewing practice style (together with convenience, as explained above). Depending on whether they want to watch together with others or individually, viewers opt to time-shift or not and employ a certain viewing practice style (live viewing, delayed viewing, downloading or DVD viewing). Furthermore, the interaction with fellow viewers is also decisive in whether or not participants engage with cross-media extensions of TV fiction. If cross-media extensions are consumed, it is often after recommendation of family, friends or other fellow viewers who follow the same TV fiction series. In line with Evans (2011), we found that digital technologies can also be seen as means to enhance and strengthen the audience. Although these new technologies expand the possibilities for asynchronous viewing and thereby might influence the social aspect of watching television simultaneously, they also offer additional possibilities to keep up to date with TV programmes and to connect with fellow viewers. Recording technologies and catchup possibilities can be used to reinforce the 'audience community', by ensuring that every viewer has access to the content. Online platforms connected to downloading services can function as facilitators of interpersonal relationships, enhancing the viewer's ability to perform as a member of the audience of a particular TV programme. Overall, our research shows that digital convergence has not caused a radical shift from social television to individualized 'me TV'.

To sum up, and echoing Lotz's (2007, p. 245) statement about the five Cs of post-network television (choice, control, convenience, customization, and community), it would have been nice to conclude this article with the three Cs of viewer engagement with cross-media fiction: convenience, convergence and community. However, our findings suggest that our participants' engagement is rather characterized by convenience, divergence, and community. First, convenience determines how participants engage with television as a technology. The viewing practices with regard to the TV fiction episodes involve control for the broadcaster or control for the viewer, depending on which mode of viewing is considered to be most convenient at that moment. Second, with regard to the dimension of the TV text, a shift was predicted from a single medium TV fiction text to extended multi-media (cross) fiction texts in a converged media landscape. However, the results show that the participants perceive a divergence between the TV series, as the central text, and its cross-media extensions. Third, as digitization increases the possibilities for a highly personalized and individualized television experience, it was expected that the medium would lose its status as social and unifying medium. Yet, it seems that a community feeling is still of key importance to viewers, who regard the social dimension of the TV fiction experience as essential.

To conclude, it is necessary to reflect on some limitations of this study. Firstly, it is not justified to make general statements based on this research with a very specific sample of engaged viewers in relation to a particular genre, fiction. How the viewers in this study experience cross-media TV fiction might not accurately capture about how these viewers engage with other types of programmes. Furthermore, the results of this research might not apply to how other, less engaged viewers experience TV fiction. Still, our conclusionswhich reveal continuity and stability rather than drastic change-indicate that one should be very cautious about making bold statements about how the television viewing behaviour of the mainstream, less engaged, audience has changed. Second, television is constantly changing. Although this does not mean that the ways of engaging with television are continuously being replaced by new ways, it does have its consequences for empirical audience research. Thus, the data for this research were gathered between 2007 and 2011, before tablets became a common household item and Netflix was launched in Belgium, among other new ways of engaging with TV fiction. Thirdly, this research was conducted in a specific geographic and cultural setting, Flanders. Differences in reception between Flemish and U.S. cross-media TV fiction, such as the lack of knowledge about and consumption of crossmedia extensions for U.S. TV fiction, might be the result of the delay in broadcast transmission and the much smaller-scale marketing campaigns of U.S. TV fiction (Catania, 2010). To summarise, the findings of this research should be contextualized and generalizing statements should be avoided. What we offer is a time and location bound analysis on how TV fiction is experienced, and we believe that it is actually the very specificity of our concrete, empirical and contextualised results that make this research a valuable counterweight to more abstract and generalizing writing on the topic.

\section{Conflict of Interests}

The authors declare no conflict of interests. 


\section{References}

Aronson, J. E., Reddy, S. K., \& Stam, A. (1998). SPOT: Scheduling programs optimally for television. Management Science, 44(1), 83-102.

Askwith, I. D. (2007). Television 2.0: Reconceptualizing $T V$ as an engagement medium. (Master Thesis). Massachusetts Institute of Technology, Cambridge, MA.

Barkhuus, L. (2009). Television on the internet: New practices, new viewers. Paper presented at the Conference of Human Factors in Computing Systems, Boston, MA, USA.

Bennett, J. (2011). Introduction: television as digital media. In J. Bennett \& N. Strange (Eds.), Television as digital media (pp. 1-27). Durham and London: Duke University Press.

Boccia Artieri, G. (2012). Productive publics and transmedia participation. Participations: Journal of Audience and Reception Studies, 9(2), 448-468.

Brereton, P. (2007). Editorial: the consumption and use of DVDs and their add-ons. Convergence: The International Journal of Research into New Media Technologies, 13(2), 115-117.

Brooker, W. (2001). Living on Dawson's Creek: Teen viewers, cultural convergence, and television overflow. International Journal of Cultural Studies, 4(4), 456-472.

Buonanno, M. (2008). The age of television: Experiences and theories. Bristol: Intellect Books.

Caldwell, J. T. (2006). Convergence television: aggregating form and repurposing content in the culture of conglomeration. In L. Spigel \& J. Olsson (Eds.), Television after TV: Essays on a medium in transition (pp. 41-74). Durham \& London: Duke University Press.

Carlson, M. (2006). Tapping into TiVo: Digital video recorders and the transition from schedules to surveillance in television. New Media \& Society, 8(1), 97115.

Catania, A. (2010, January). Transmedia Europe? US multiplatform franchises on Euorpean screens. Paper presented at the conference on Contemporary Serial Culture: Quality TV in a New Media Environment, Potsdam-Babelsberg, Germany.

Clarke, M. J. (2009). The strict maze of media tie-in novels. Communication, Culture and Critique, 2, 434-456.

Creswell, J. W. (1998). Qualitative inquiry and research design: Choosing among five traditions. Thousand Oaks: Sage Publications.

Ellis, J. (2000). Seeing things: Television in the age of uncertainty. London: I.B. Tauris \& Co Ltd.

Evans, E. J. (2008). Audiences for emergent transmedia drama. University of London, London.

Evans, E. J. (2011). Transmedia television. Audiences, new media and daily life. New York, NY: Routledge.

Gray, J. (2008). Television entertainment. New York: Routledge.
Gray, J. (2010). Show sold separately: Promos, spoilers, and other media paratexts. NY: New York University.

Gripsrud, J. (2010). Television in the digital public sphere. In J. Gripsrud (Ed.), Relocating television: Television in the digital context (pp. 3-26). New York: Routledge.

Hoppenstand, G. (2006). Editorial: 'Me' TV. The Journal of Popular Culture, 39(5), 707-708.

Jenkins, H. (2003). Transmedia storytelling. Technology Review, January. Retrieved from http://www.tech nologyreview.com

Jenkins, H. (2006). Convergence culture: Where old and new media collide. New York: New York University Press.

Kackman, M., Binfield, M., Payne, M. T., Perlman, A., \& Sebok, B. (2011). Introduction. In M. Kackman, M. Binfield, M. T. Payne, A. Perlman, \& B. Sebok (Eds.), Flow TV. Television in the age of media convergence (pp. 1-10). New York: Routledge.

Katz, E. (2009). Introduction: The end of television. In E. Katz \& P. Scannell (Eds.), The annals of the American academy of political and social science (Vol. 625, pp. 6-18). Thousand Oaks, CA: Sage Publications.

Lotz, A. D. (2007). The television will be revolutionized. New York: New York University Press.

Lotz, A. D. (2009a). Introduction. In A. D. Lotz (Ed.), Beyond prime time: Television programming in the post-network era (pp. 1-13). New York: Routledge.

Lotz, A. D. (2009b). What is U.S. television now? In E. Katz \& P. Scannell (Eds.), The annals of the American academy of political and social science (Vol. 625, pp. 49-59). Thousand Oaks, CA: Sage Publications.

Mittell, J. (2011). TiVoing childhood. Time-shifting a generation's concept of television. In M. Kackman, M. Binfield, M. T. Payne, A. Perlman, \& B. Sebok (Eds.), Flow TV. Television in the age of media convergence (pp. 46-54). New York: Routledge.

Ritchie, J., Lewis, J., \& Elam, G. (2003). Designing and selecting samples. In J. Ritchie \& J. Lewis (Eds.), Qualitative research practice: A guide for social science students and researchers (pp. 77-108). London: Sage Publications.

Rogers, M. C., Epstein, M. M., \& Reeves, J. L. (2002). The Sopranos and HBO brand equity. The art of commerce in the age of digital reproduction. In D. Lavery (Ed.), This thing of ours: Investigating The Sopranos (pp. 42-60). New York: Columbia University Press.

Simons, N. (2013). Watching TV fiction in the age of digitization: A study into the viewing practices of engaged TV fiction viewers. International Journal of Digital Television, 4(2), 177-191

Simons, N. (2014). Audience reception of cross- and transmedia TV drama in the age of convergence. International Journal of Communication, 8, 2220-2239. Retrieved from http://ijoc.org/index.php/ijoc/article/ view/2598/1207

Simons, N. (2015). TV drama as a social experience: an 
empirical investigation of the social dimensions of watching TV drama in the age of non-linear television. Communications: The European Journal of Communication Research, 40(2), 219-236.

Spigel, L., \& Olsson, J. (Eds.). (2006). Television after TV: Essays on a medium in transition. Durham \& London: Duke University Press.
Turner, G., \& Tay, J. (Eds.). (2009). Television studies after TV: Understanding television in the postbroadcast era. London: Routledge.

Van den Broeck, W., Pierson, J., \& Lievens, B. (2007). Video-On-Demand: Towards new viewing practices? Observatorio, 1(3), 23-44.

\section{About the Authors}

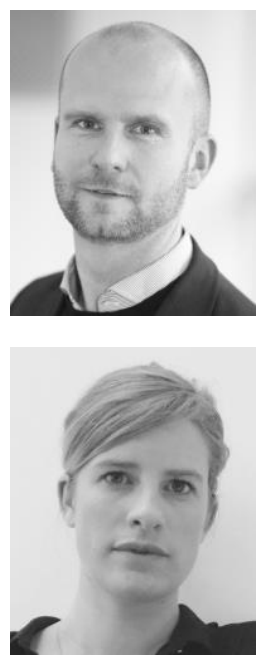

\section{Dr. Alexander Dhoest}

Alexander Dhoest (M.A. in Communication Studies, KU Leuven; M.A. in Film and Television Studies, University of Warwick; Ph.D. in Social Sciences, KU Leuven) is associate professor and head of the department of Communication Studies at the University of Antwerp. His research deals with the production and reception of media (including television), focusing in particular on its role in processes of identification.

\section{Dr. Nele Simons}

Nele Simons (M.A. in Communication Studies, University of Antwerp, Ph.D. in Social Sciences, University of Antwerp) does research on television culture and media convergence. In her Ph.D. research, she explored how viewers engage with TV drama, paying particular attention to the role of TV drama add-ons in viewers' television viewing practices. 